УДК 502.753

ОХРАНЯЕМЫЕ ОРХИДНЫЕ В КЕМЕРОВСКОМ РАЙОНЕ

Любовь Н. Ковригина ${ }^{1, @ 1}$, Александра В. Филиппова ${ }^{1,2}$, Наталья Г. Романова ${ }^{1, @ 3}$, Буяна О. Монгуш

${ }^{1}$ Кемеровский государственный университет, Россия, 650000, г. Кемерово, ул. Красная, 6

@11nkovrigina@mail.ru

@2sasha1977@ngs.ru

@3 chatn@yandex.ru

Поступила в редакичию 30.11.2017. Принята к печати 27.12.2017.

\section{Ключевые слова:}

Кемеровская область, орхидные, популяция, виталитет, пространственное размещение, возрастная структура.

\begin{abstract}
Аннотация: Из 27 видов орхидных, произрастающих на территории Кемеровской области, 20 включены в Красные книги Российской Федерации и Кемеровской области. Объективная оценка состояния вида и разработка эффективных мер охраны предполагает учет местонахождений, оценку состояния популяций и условий их существования. В статье дана характеристика видового состава, жизненных форм, экологических особенностей охраняемых видов семейства Орхидные, найденных в Кемеровском районе. Изучено состояние популяций пальчатокоренника Фукса (Dactylorhiza fuchsii (Druce) Soo) и ятрышника шлемоносного (Orchis militaris L.) во время их цветения. Закладывали трансекты из 25 примыкающих квадратных площадок площадью в 1 м². На каждой площадке подсчитывали число особей, определяли их возрастное состояние, измеряли высоту цветущих растений, длину соцветия и листа. В популяциях орхидных выделяли ювенильные, имматурные, виргинильные, генеративные особи. Определяли жизненное состояние особей, характеризовали возрастной и виталитетный спектры, а также пространственную структуру популяций. Состояние популяции Orchis militaris L. определено как удовлетворительное, популяции Dactylorhiza fuchsii (Druce) Soo - как плохое.
\end{abstract}

Для цитирования: Ковригина Л. Н., Филиппова А. В., Романова Н. Г., Монгуш Б. О. Охраняемые орхидные в Кемеровском районе // Вестник Кемеровского государственного университета. Серия: Биологические, технические науки и науки о Земле. 2017. № 4. C. 4-8. DOI: 10.21603/2542-2448-2017-4-4-8.

Растения из семейства Орхидные в силу своих эколого-биологических особенностей (слабое семенное размножение, микотрофность, низкая конкурентоспособность, узкая экологическая амплитуда) являются очень уязвимым компонентом флоры, многие из них занесены в Красные книги Российской Федерации и регионов [1].

На территории Кемеровской области произрастает 27 видов орхидных, относящихся к 17 родам [2], 20 из них включены в Красную книгу Кемеровской области, 7 в Красную книгу Российской Федерации. Лимитирующими факторами для орхидей являются уничтожение и изменение условий обитания, а также повреждение растений вследствие выпаса, сенокошения, рекреации и сбора на букеты $[1 ; 3]$. Объективная оценка состояния вида и разработка эффективных мер охраны предполагает учет местонахождений, оценку состояния популяций и условий их существования [4]. В открытой печати отсутствуют сведения о состоянии популяций видов семейства Орхидные флоры Кемеровского района.

Цель работы: выявление местонахождений популяций охраняемых орхидных в Кемеровском районе и оценка их состояния.

При составлении списка орхидных Кемеровского района были проанализированы материалы гербария Кемеровского государственного университета (КЕМ), база данных «Растения, грибы и лишайники Красной книги Кемеровской области» [5] и литературные источники $[1 ; 3 ; 6 ; 7]$.
Популяционные исследования были проведены в окрестностях с. Березово Кемеровского района в 2016 г. Изучено состояние популяций пальчатокоренника Фукса (Dactylorhiza fuchsii (Druce) Soo) и ятрышника шлемоносного (Orchis militaris L.) во время их цветения летом 2016 г.

Для определения популяционных и организменных параметров закладывали трансекты из 25 примыкающих квадратных площадок площадью в 1 м². На каждой площадке подсчитывали число особей, определяли их возрастное состояние [8; 9], измеряли высоту цветущих растений (см) у обоих видов, длину соцветия (см), длину и ширину (см) листа - у пальчатокоренника Фукса. В популяциях орхидных выделяли следующие возрастные группы особей: ювенильные (j), имматурные (im), виргинильные (v), генеративные (g). В качестве ключевых были выбраны признаки их надземных частей: наличие соцветий, число и форма листьев, число жилок. При обработке данных вычисляли среднюю численность и среднюю плотность (шт./M²), определяли жизненное состояние особей, а затем характеризовали возрастной и виталитетный спектры, а также пространственную структуру популяций. Особенности размещения растений определяли с помощью индекса Одума $\left(\mathrm{I}_{\mathrm{Od}}\right)$, при оценке жизненного состояния использовали индекс IQ [10].

Анализ литературных данных [3; 6; 7] и гербарной коллекции $[5 ; 11 ; 12]$ показал, что на территории Кемеровского района произрастает 13 видов орхидей: Cypripedium 
calceolus L., Cypripedium guttatum Sw., Cypripedium macranthon Sw., Dactylorhiza baltica (Klinge) Orlova, Dactylorhiza fuchsii (Druce) Soo, Dactylorhiza incarnata (L.) Soo, Epipactis helleborine (L.) Crantz, Epipactis palustris (L.) Crantz, Listera ovata (L’.) R. Br., Malaxis monophyllos (L.) Sw., Neottia nidus-avis (L.) Rich., Orchis militaris L., Platantera bifolia (L.) Rich.

11 видов включены в Красную книгу Кемеровской области: C. calceolus, C. guttatum, C. macranthon, D. baltica, D. fuchsii, E. helleborine, E. palustris, L. ovata, M. monophyllos, $N$. nidus-avis, O. militaris, т. е. $55 \%$ из всех охраняемых орхидных нашего региона [3]. C. calceolus, C. macranthon, D. baltica, O. militaris подлежат охране на государственном уровне [1].

Популяции охраняемых видов орхидных были найдены в окрестностях следующих населенных пунктов: д. Подъяково (D. fuchsii, E. helleborine), д. Журавлево (C. guttatum), г. Кемерово (C. macranthon, E. helleborine, L. ovata), пос. Звездный (E.palustris), с. Верхотомское (D. baltica, N.nidusavis), д. Сухая речка (C. calceolus), быв. пос. Городок (D. fuchsii, M. monophyllos), c. Березово (D. fuchsii, E. helleborine, L. ovata, O. militaris) (KEM, [3; 5-7; 11; 12]).

В Кемеровском районе зарегистрировано по 3 популяции D. fuchsii, E. helleborine, две - L. ovata, по одной - остальных видов. Но только 3 местонахождения и 6 популяций четырех видов: в окрестностях г. Кемерово (L. ovata), в окрестностях быв. пос. Городок (D. fuchsii), в окрестностях с. Березово (E. helleborine, D. fuchsii, L. ovata, O. militaris), были обнаружены после 2010 г. [7]. В отношении остальных, найденных до 2000 г., требуется подтверждение их сохранности.

Среди охраняемых орхидных флоры Кемеровского района преобладают корневищные растения: C. calceolus, C. guttatum, C. macranthon, E. helleborine, E. palustris, L. ovata, N. nidus - avis. Остальные относятся к тубероидным: D. baltica, D. fuchsii, M. monophyllos, O. militaris. У первых при проведении популяционных исследований счетной единицей служит побег, у последних - особь. Корневищные орхидеи могут размножаться как семенным, так и вегетативным путем. Главным механизмом увеличения численности и поддержания популяций тубероидных орхидных является семенное размножение, поэтому часто критическое состояние этих видов связано с условиями, снижающими реальную семенную продуктивность и выживаемость особей пререпродуктивного периода.

Среди охраняемых орхидных, произрастающих в Кемеровском районе, выделены 2 экогруппы по отношению к влаге: 8 видов произрастают в средних условиях увлажнения, 3 вида лучше развиваются при повышенной влажности почвы (D. baltica, E. palustris, M. monophyllos). К кальцефилам относятся 2 вида: C. calceolus $и$ O. militaris. Максимальным числом видов представлены мезотрофы (7 видов), 1 вид - эвтроф (N. Nidus-avis). 3 вида могут расти на различных по уровню плодородия почвах: как со средним, так и с высоким (C. calceolus, L. ovata) или низким (E.palustris) содержанием элементов питания. Сапрофиты представлены одним видом: Neottia nidusavis. 6 видов относятся к теневыносливым, 2 вида-светолюбивы (D. baltica, O. militaris), 3 вида - тенелюбивые (C. calceolus, M. monophyllos, N. nidus-avis). Большинство видов являются стеновалентными по отношению к уровню увлажнения, а D. fuchsii и O. militaris - еще и к кислот- ности почвы (не переносят кислых почв). Виды изучаемой группы произрастают преимущественно в лесах, на лесных полянах и среди кустарников.

В 2016 г. в окрестностях с. Березово было обнаружено 4 вида охраняемых орхидей: D. fuchsii, E. helleborine, L. ovata, O. militaris. Причем местонахождение ятрышника шлемоносного в Кемеровском районе было найдено впервые [3; 6; 7]. Популяции сформировались на экотонном участке по обочине автомобильной дороги, который характеризуется выраженным микрорельефом, повышенным увлажнением и развитием травянистой и кустарниковой растительности.

Популяции E. helleborine и L. ovata - малочисленные и представлены 9 и 7 счетными единицами (соответственно), занимая площадь в несколько м². Популяции D. fuchsii и O. militaris были достаточно крупными, что позволило провести изучение их возрастной, виталитетной и пространственной структуры. Счетными единицами у этих видов, как и у других тубероидных орхидных, служили особи.

Площадь популяционного поля пальчатокоренника

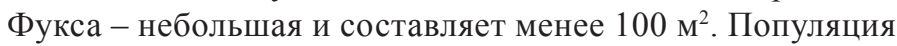
ятрышника шлемоносного занимает территорию более

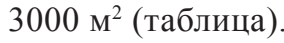

Средняя плотность популяции у второго вида почти в 3 раза выше, чем у первого (4,7 против 1,6 шт./ $\left.{ }^{2}\right)$. В связи с этим средняя численность второго вида превышает 16 тыс. экземпляров, а первого - составляет менее 200 экз. Популяции численностью до 100 экз. относят к малочисленным, свыше 500 экз. - к многочисленным, численность от 100 до 500 экз. считается средней [10]. По совокупности таких показателей, как площадь и численность, состояние популяции ятрышника шлемоносного можно определить как удовлетворительное, а пальчатокоренника Фукса - как плохое [10].

При оценке пространственного размещения счетных единиц в популяции с помощью индекса Одума принята следующая градация: $\mathrm{I}_{\text {Od }}=1$ - распределение случайное, $\mathrm{I}_{\mathrm{Od}}<1-$ равномерное, $\mathrm{I}_{\mathrm{Od}}>1-$ групповое [10].

Размещение особей в популяции обоих видов - контагиозное $\left(\mathrm{I}_{\mathrm{Od}}>1\right)$, причем у ятрышника шлемоносного размещение растений группами выражено сильнее, чем у пальчатокоренника Фукса, так как значение индекса Одума почти в 2 раза выше (таблица).

Изучение возрастного спектра популяции позволяет оценить способность вида к самоподдержанию в данных условиях среды.

В популяции пальчатокоренника Фукса обнаружены виргинильные (с 2-3 крупными продолговато-ланцетными листьями) и генеративные растения. Причем доля первых $(56,0 \%)$ больше, чем вторых $(44,0 \%)$, т. е. возрастной спектр неполночленный, характеризующийся отсутствием ювенильных и имматурных экземпляров. Сенильные растения отсутствовали, что характерно для данного вида. Судя по наличию в возрастном спектре генеративных растений, популяция существует не менее 4-х лет, так как этот вид в зависимости от условий обитания зацветает через 4-14 лет после первого появления над землей [13]. Преобладание виргинильных растений характерно для данного пальчатокоренника Фукса [13], а отсутствие ювенильных и имматурных может объясняться нерегулярным семенным возобновлением в данной популяции. 
Вестник КемГУ • Серия: Биологические, технические науки и науки о Земле• 2017 • № 4

Таблица. Популяционные и организменные показатели пальчатокоренника Фукса и ятрышника шлемоносного Table. Population and organism indices of the Fuchs fingergrass and the orchis of the helmet

\begin{tabular}{|c|c|c|c|c|}
\hline \multirow{2}{*}{ Признак } & \multicolumn{2}{|c|}{ Пальчатокоренник Фукса } & \multicolumn{2}{|c|}{ Ятрышник шлемоносный } \\
\hline & среднее значение признака & $\mathrm{I}_{0}$ & среднее значение признака & $\mathrm{I}_{0}$ \\
\hline Высота растения, см & $51,1 \pm 2,34$ & 0,7 & $23,8 \pm 1,19$ & 0,7 \\
\hline Длина листа, см & $16,2 \pm 0,53$ & 0,8 & - & - \\
\hline Ширина листа, см & $2,5 \pm 0,15$ & 0,5 & - & - \\
\hline Длина соцветия, см & $9,7 \pm 0,54$ & 0,9 & - & - \\
\hline Средняя плотность, шт./м² & $1,6 \pm 0,51$ & - & $4,7 \pm 1,12$ & - \\
\hline $\mathrm{j}+\mathrm{im}, \%$ & 0,0 & - & 20,9 & - \\
\hline $\mathrm{v}, \%^{2}$ & 56,0 & - & 42,7 & - \\
\hline $\mathrm{g}, \%$ & 44,0 & - & 36,4 & - \\
\hline Индекс Одума & 5,1 & - & 8,9 & - \\
\hline Площадь, $\mathrm{m}^{2}$ & 90,3 & - & 3530,0 & - \\
\hline Средняя численность, шт. & 186,7 & - & 16591,0 & - \\
\hline
\end{tabular}

Возрастной спектр популяции ятрышника шлемоносного - полночленный: в нем представлены все возрастные состояния, характерные для вида. Ювенильные и имматурные растения имели по одному листу, их доля составляла $20,9 \%$. Доля виргинильных особей, имеющих по 2-3 листа, была самой высокой - 42,7 \%. Цветущие экземпляры генеративной фракции составляли 36,4 \% от численности популяции, сенильные растения отсутствовали. Преобладание прегенеративной и отсутствие постгенеративной фракции в возрастном спектре отмечалось при изучении популяционной структуры вида и другими исследователями [9]. Судя по присутствию генеративных растений, данная популяция существует не менее 7 лет, так как ятрышник шлемоносный зацветает на 7-8 год жизни [13]. В популяции представлены все онтогенетические состояния, что свидетельствует о регулярном семенном возобновлении и благоприятных условиях для развития особей как прегенеративного, так и генеративного периодов.

Для популяций характерна дифференциация их элементов по жизненному состоянию, т. е. размерам, устойчивости к неблагоприятным воздействиям, интенсивности обмена веществ и т. д. Соотношение особей с различным уровнем развития характеризует виталитетную структуру популяций, отражающую первичные изменения в них. Индекс $\mathrm{I}_{\mathrm{Q}}$ позволяет разделить их на процветающие $\left(\mathrm{I}_{\mathrm{Q}}>1\right)$, равновесные $\left(\mathrm{I}_{\mathrm{Q}}=1\right)$ и депрессивные $\left(\mathrm{I}_{\mathrm{Q}}<1\right)[10]$.

В популяции пальчатокоренника Фукса была высока доля особей низшего класса жизненности: 42,1 \% - по высоте растений, 39,2 \% - по длине листа, 50,0 \% - по ширине листа, $35,7 \%$ - по длине соцветия. В связи с этим значения индекса $\mathrm{I}_{\mathrm{Q}}$ по показателям развития вегетатив- ной и генеративной сферы ниже $1,0(0,5-0,9)$, что характеризует данную популяцию как депрессивную.

К группе с высоким уровнем жизненности в популяции ятрышника шлемоносного были отнесены экземпляры высотой более 26,3 см, их доля составила 52,7 \%. Растения высотой менее 21,3 см, вошли в группу низшего класса виталитета $(43,0$ \%). Численность средней группы была минимальной $\left(4,3\right.$ \%). Индекс $\mathrm{I}_{\mathrm{Q}}$ по этому признаку был близок к пальчатокореннику Фукса - 0,67, т. е. популяция ятрышника шлемоносного также относится к депрессивным по показателю, характеризующему развитие вегетативной сферы.

Таким образом, в Кемеровском административном районе произрастает 13 видов орхидных, 11 из них занесены в Красную книгу Кемеровской области, 4 - в Красную книгу Российской Федерации. За период с 1969 по 2017 годы в районе обнаружено 22 местонахождения орхидных, для 19 из которых в настоящее время требуется подтверждение существования популяций. В 2016 г. проведена оценка состояния 2-х популяций в одном локалитете (в окрестностях с. Березово). На момент наблюдения популяция Orchis militaris характеризуется как крупная, многочисленная, с регулярным семенным возобновлением. Популяция Dactylorhiza fuchsii - небольшая, средняя по численности, отличается нерегулярным семенным возобновлением. На момент обследования выявлены признаки депрессии обеих популяций, выражающиеся в снижении их жизненного состояния. Однако однократная оценка не позволяет определить характер и масштаб отклонений изучаемых параметров от оптимума и достоверно выявить лимитирующие факторы. В связи с этим необходимо продолжить изучение популяционных и организменных показателей в динамике.

\section{Литература}

1.Красная книга Российской Федерации (растения и грибы) / Министерство природных ресурсов и экологии РФ; Федеральная служба по надзору в сфере природопользования; РАН; Российское ботаническое общество; МГУ им. М. В. Ломоносова. М.: Товарищество научных изданий КМК, 2008. 885 с.

2. Красноборов И. М., Крапивкина Э. Д., Ломоносова М. Н., Будникова Г. П., Шауло Д. Н., Волобаев П. А., Мальцева А. Т., Яковлева Г. И., Красников А. А., Вибе Е. И., Доронькин В. М., Байков К. С., Тупицына Н. Н., Герман Д. А., Вылцан Н. Ф., Гуреева И. И. Определитель растений Кемеровской области. Новосибирск: Изд-во СО РАН, 2001.477 с. 
3. Буко Т. Е., Горбунова И. А., Егоров А. Г., Климов А. В., Котиранта Х., Крапивкина Э. Д., Куприянов А. Н., Мальцева А. Т., Манаков Ю. А., Ножинков А. Е., Писаренко О. Ю., Седельникова Н. В., Стрельникова Т. О., Шереметова С. А., Ширяев А. Г., Щёголева Н. В., Эбель А. Л., Яковлева Г. И. Красная книга Кемеровской области. Т. 1. Редкие и находящиеся под угрозой исчезновения виды растений и грибов / 2-е изд., перераб. и доп. Кемерово: Азия принт, 2012.206 с.

4. Романова Н. Г., Ковригина Л. Н., Филиппова А. В., Тарасова И. В. Состояние популяций Serratula marginata (Asteraceae) в Кемеровской области // Сохранение разнообразия растительного мира в ботанических садах: традиции, современность, перспективы: материалы Международной конференции, посвященной 70-летию Центрального сибирского ботанического сада (Новосибирск, 1-8 августа 2016 г.). Новосибирск: ЦСБС СО РАН, 2016. С. 256-257.

5. Ковригина Л. Н., Романова Н. Г., Филиппова А. В. Растения, грибы и лишайники Красной книги Кемеровской области: база данных. Номер гос. рег. 2017620694 от 30.06.2017.

6. Ковригина Л. Н., Филиппова А. В., Тарасова И. В., Романова Н. Г. Уточнение местонахождений охраняемых растений по материалам гербария Кемеровского государственного университета // Вестник Кемеровского государственного университета. Серия: Биологические, технические науки и науки о Земле. 2017. № 1. С. 10-15.

7. Ковригина Л. Н., Романова Н. Г., Филиппова А. В., Тарасова И. В. Новые местонахождения охраняемых растений и грибов в Кемеровской области // Экология и управление природопользованием: сборник научных трудов Первой всероссийской научно-практической конференции с международным участием / под ред. А. М. Адама. Томск, 2017. Вып. 1. С. 123-124.

8. Вахрамеева М. Г., Денисова Л. В. Особенности онтогенеза и динамика численности ценопопуляций двух видов рода Dactylorhiza // Охрана и культивирование орхидей. М., 1987. С. 22-24.

9. Фардеева М. Б. Онтогенез ятрышника шлемоносного (Orchis militaris L.) // Онтогенетический атлас лекарственных растений. Йошкар-Ола: МарГУ, 2002. Т. 3. С. 287-242.

10. Злобин Ю. А., Скляр В. Г., Клименко А. А. Популяция редких видов растений, теоретические основы и методика изучения. Сумы: Университетская книга, 2013. 440 с.

11. Ковригина Л. Н., Иванов В. И., Романова Н. Г., Филиппова А. В., Тарасова И. В. Кадастр высших растений Кемеровской области. Свидетельство о регистрации базы данных RUS 2017621117 от 01.08.2017.

12. Ковригина Л. Н., Иванов В. И., Романова Н. Г., Филиппова А. В., Тарасова И. В. Программа управления базой данных «Кадастр высших растений Кемеровской области» Kadastr VRKO. Свидетельство о регистрации программы для ЭВM RUS 2017660731 от 01.08.2017.

13. Вахрамеева М. Г., Варлыгина Т. И., Татаренко И. В. Орхидные России (Биология, экология и охрана). М.: Тов-во научных изданий КМК, 2014. 474 с.

\title{
PROTECTED ORCHIDS IN THE KEMEROVO DISTRICT
}

\section{Lyubov N. Kovrigina, @1, Alexandra V. Filippova, @2, Natalia G. Romanova1, @3, Bujana O. Mongush ${ }^{1}$}

\author{
${ }^{1}$ Kemerovo State University, 6, Krasnaya St., Kemerovo, Russia, 650000 \\ @1lnkovrigina@mail.ru \\ @2sasha1977@ngs.ru \\ @3.chatn@yandex.ru
}

Received 30.11.2017. Accepted 27.12.2017.

Keywords: Kemerovo region, Orchids, population, vitality, spatial arrangement, age structure.

\begin{abstract}
Of the 27 species of orchids growing in the Kemerovo region, 20 are included in the Red books of The Russian Federation and the Kemerovo region. An objective assessment and development of effective protection measures involves consideration of the location, population assessment and evaluation of the conditions. The article features characteristics of species composition, biomorphs, ecological features of the protected Orchidaceae species in the Kemerovo district. The research focused on the population status of Dactylorhiza fuchsii (Druce) Soo and Orchis militaris L. at the time of their flowering. The process involved setting transects consisting of 25 adjacent square pads with an area of $1 \mathrm{~m}^{2}$ each. The number of specimen was calculated on each site; their age and status were determined; the height of flowering plants, the length of the inflorescence and leaf were measured. Juvenile, immature, virginile and generative specimen were defined in each population of orchids. The authors determined the vital status of specimens, characterized the age and vitality spectrum, as well as the spatial structure of the populations. The population status Orchis militaris L. is defined as satisfactory, whereas the population of Dactylorhiza fuchsii (Druce) Soo was assessed as bad.
\end{abstract}

For citation: Kovrigina L. N., Filippova A. V., Romanova N. G., Mongush B. O. Okhraniaemye orkhidnye v Kemerovskom raione [Protected Orchids in the Kemerovo District]. Bulletin of Kemerovo State University. Series: Biological, Engineering and Earth Sciences, no. 4 (2017): 4-8. DOI: 10.21603/2542-2448-2017-4-4-8. 


\section{References}

1. Krasnaia kniga Rossiiskoi Federatsii (rasteniia i griby) [The Red Book of the Russian Federation (plants and mushrooms)]. Moscow: Tovarishchestvo nauchnykh izdanii KMK, 2008, 885.

2. Krasnoborov I. M., Krapivkina E. D., Lomonosova M. N., Budnikova G. P., Shaulo D. N., Volobaev P. A., Mal'tseva A. T., Iakovleva G. I., Krasnikov A. A., Vibe E. I., Doron'kin V. M., Baikov K. S., Tupitsyna N. N., German D. A., Vyltsan N. F., Gureeva I. I. Opredelitel' rastenii Kemerovskoi oblasti [Plants of the Kemerovo region]. Novosibirsk: Izd-vo SO RAN, $2001,477$.

3. Buko T. E., Gorbunova I. A., Egorov A. G., Klimov A. V., Kotiranta Kh., Krapivkina E. D., Kupriianov A. N., Mal'tseva A. T., Manakov Iu. A., Nozhinkov A. E., Pisarenko O. Iu., Sedel'nikova N. V., Strel'nikova T. O., Sheremetova S. A., Shiriaev A. G., Shchegoleva N. V., Ebel' A. L., Iakovleva G. I. Krasnaia kniga Kemerovskoi oblasti. T. 1. Redkie i nakhodiashchiesia pod ugrozoi ischeznoveniia vidy rastenii i gribov [Red Book of the Kemerovo Region. Vol. 1. Rare and endangered species of plants and fungi]. 2nd ed. Kemerovo: Aziia print, 2012, 206.

4. Romanova N. G., Kovrigina L. N., Filippova A. V., Tarasova I. V. Sostoianie populiatsii Serratula marginata (Asteraceae) v Kemerovskoi oblasti [The population status of Serratula marginata (Asteraceae) in the Kemerovo region]. Sokhranenie raznoobraziia rastitel'nogo mira v botanicheskikh sadakh: traditsii, sovremennost', perspektivy: materialy Mezhdunarodnoi konferentsii, posviashchennoi 70-letiiu Tsentral'nogo sibirskogo botanicheskogo sada (Novosibirsk, 1-8 avgusta 2016 g.) [The conservation of plant biodiversity in Botanical gardens: tradition, contemporaneity, prospects: Proc. Intern. Conf. dedicated to the 70th anniversary of the Central Siberian Botanical garden (Novosibirsk, 1-8 August 2016)]. Novosibirsk: TsSBS SO RAN, 2016, 256-257.

5. Kovrigina L. N., Romanova N. G., Filippova A. V. Rasteniia, griby i lishainiki Krasnoi knigi Kemerovskoi oblasti [Plants, fungi and lichens of the Red Book of the Kemerovo Region: database]. State registration number 2017620694 dated June $30,2017$.

6. Kovrigina L. N., Filippova A. V., Tarasova I. V., Romanova N. G. Utochnenie mestonakhozhdenii okhraniaemykh rastenii po materialam gerbariia Kemerovskogo gosudarstvennogo universiteta [Location update of protected plants according to herbarium materials of the Kemerovo State University]. Bulletin of Kemerovo State University. Series: Biological, Engineering and Earth Sciences, no. 1 (2017): 10-15.

7. Kovrigina L. N., Romanova N. G., Filippova A. V., Tarasova I. V. Novye mestonakhozhdeniia okhraniaemykh rastenii i gribov v Kemerovskoi oblasti [New locations of protected plants and fungi in the Kemerovo Region]. Ekologiia i upravlenie prirodopol'zovaniem: sbornik nauchnykh trudov Pervoi vserossiiskoi nauchno-prakticheskoi konferentsii s mezhdunarodnym uchastiem [Ecology and environmental management: Proc. First All-Russian Sc.-Prac. Conf. with Intern. participation]. Ed. Adam A. M. Tomsk, Iss. 1 (2017): 123-124.

8. Vakhrameeva M. G., Denisova L. V. Osobennosti ontogeneza i dinamika chislennosti tsenopopuliatsii dvukh vidov roda Dactylorhiza [Peculiarities of ontogenesis and the dynamics of the number of cenopopulations of two species of the genus Dactylorhiza]. Okhrana i kul'tivirovanie orkhidei [Protection and cultivation of orchids]. Moscow, 1987, $22-24$.

9. Fardeeva M. B. Ontogenez iatryshnika shlemonosnogo (Orchis militaris L.) [Ontogenesis of the Orchis militaris L. (Orchis militaris L.)]. Ontogeneticheskii atlas lekarstvennykh rastenii [Ontogenetic atlas of medicinal plants]. Yoshkar-Ola: MarGU, vol. 3 (2002): 287-242.

10. Zlobin Iu. A., Skliar V. G., Klimenko A. A. Populiatsiia redkikh vidov rastenii, teoreticheskie osnovy i metodika izucheniia [Population of rare plant species, theoretical bases and methods of studying]. Sumy: Universitetskaia kniga, $2013,440$.

11. Kovrigina L. N., Ivanov V. I., Romanova N. G., Filippova A. V., Tarasova I. V. Kadastr vysshikh rastenii Kemerovskoi oblasti [Cadastre of higher plants of the Kemerovo region]. Certificate of registration of the database RUS 2017621117 dated 01.08.2017.

12. Kovrigina L. N., Ivanov V. I., Romanova N. G., Filippova A. V., Tarasova I. V. Programma upravleniia bazoi dannykh «Kadastr vysshikh rastenii Kemerovskoi oblasti» Kadastr VRKO [Database management program «Cadastre of higher plants of the Kemerovo region» Kadastr VRKO]. Certificate of registration of the computer program RUS 2017660731 dated 01.08.2017.

13. Vakhrameeva M. G., Varlygina T. I., Tatarenko I. V. Orkhidnye Rossii (Biologiia, ekologiia i okhrana) [Orchid of Russia (Biology, Ecology and Protection)]. Moscow: Tov-vo nauchnykh izdanii KMK, 2014, 474. 